\title{
Flood Risk Reduction Model on Small Medium Enterprises
}

\section{Muzakar Isa and Liana Mangifera}

Faculty of Economics and Business, Universitas Muhammadiyah Surakarta, Jl. A. Yani Pabelan Kartasura 57102 Surakarta

\section{Abstract}

The main risk of flood for SMEs is the damage in production equipment and production site. As the business unit that suffered the most losses due to flood, flood risk for SMEs should be reduced. This study aimed to identify who are the stakeholders involved in the existing institutions, identify interests of stakeholders involved in flood risk reduction, analyzing the influence and dependence of stakeholders in reducing flood risk, analyzing the relationship between stakeholders in efforts to reduce flood risk, modeling relationships among stakeholders in efforts to reduce flood risk for small and

Corresponding Author: Muzakar Isa

muzakar.isa@ums.ac.id

Received: 18 January 2019 Accepted: 24 March 2019 Published: 31 March 2019

Publishing services provided by Knowledge E

(c) Muzakar Isa and Liana Mangifera. This article is distributed under the terms of the Creative Commons

Attribution License, which permits unrestricted use and redistribution provided that the original author and source are credited.

Selection and Peer-review under the responsibility of the First ELEHIC Conference Committee. medium enterprises in Klaten, Central Java, Indonesia. Mixed method approach, which is the combination of quantitative and qualitative methods, was employed. Population of this study is SMEs in the flood-prone area in Klaten Regency. Structured interview was done to collect the data. Data analysis used stakeholder analysis based on the MICMAC and MACTOR program. The results of these study 13 stakeholders have crucial role in reducing flood risk. Their interests can be divided into humanity, main duty, safety, image, and income. In the effort of reducing the flood risks, BPBD together with respective village head and volunteers have the central role, while university has the lowest contribution.

Keywords: risk reduction, flood, vulnerability, stakeholders, SMEs

\section{Introduction}

Small and Medium Enterprises (SMEs) are the main pillars of the Indonesian economy. SMEs have proven resilient to the various economic crises that hit the country. SMEs have a strategic role in the structure of the economy. In the last five years the contribution of SMEs to gross domestic product (GDP) increased from 57.84 percent to 60.34 percent. Labor absorption also increased from 96.99 percent to 97.22 percent (Bank Indonesia, 2016). Nevertheless, they are the most affected units in case there is a hazard. The 
shortage in risk analysis and the complexity of post-disaster recovery are some major issues for them [1-2].

Indonesia is one of the world's most disaster-prone countries, one of which is flood hazard [3]. The occurrence of such a hazard in 1815 to 2015 is 36.94 percent of the total natural disaster in Indonesia or as many as 5.903 occurrences [4]. Central Java Province is one of provinces with high vulnerability to flood [4] and Klaten Regency is one of the most flood-prone areas in Central Java Province [4-5]. In 2011-2015, 20 floods with mayor impacts were recorded, including one victim died, 2094 people were evacuated, 7 houses and 605 ha were heavily damaged [4].

The main risk of flood for SMEs is the damage in production equipment and production site [5]. The production site is usually integrated to the settlement hence the priority of protecting the production site is simultaneous with protecting the residence. As the business unit that suffered the most losses due to flood, SMEs have not taken special measures to anticipate flooding. In general, they merely set aside small amount of the income to anticipate and devise work standard procedures $[1,6]$

The risk of flooding for SMEs should be reduced. The high risk has adverse effect on the regional income and the labor absorption, and ultimately on the regional economic growth [5]. Nevertheless, regional economic growth is the main indicator of the achievement of regional development. Isa [7] described the frequency and duration of floods influence the magnitude of the risk of flooding. Inevitably, flood brings a lot of damage to the factors of production and losses that certainly affect the economic growth. Flood risk reduction should be undertaken to maintain regional economic growth.

Swart and Frank [8] and Isa [5] explicated the risk of flooding is linked to hazard and vulnerability. Vulnerability is a condition that causes the incapability of SMEs in facing the peril of flood. It is assumed as a major determinant of disaster risk, since hazard does not necessarily bring any risk unless it interacts with vulnerable physical, social and economic environment [9]. The attempt to reduce flood risk on SMEs can be done by diminishing the vulnerability of a region. It requires the identification of regional vulnerability to the flood.

Optimal and continuous flood risk reduction involves the cooperation and synergy among stakeholders to decrease the vulnerability level of a region. So far, study on the vulnerability aspects of Klaten regency over flood has not been done. It may be a cause for the sub-optimal flood risk reduction in Klaten regency. In addition to the vulnerability aspects, study on the prospective main stakeholders and the relationships among stakeholders in flood risk reduction has not been done either. Each stakeholder relatively has respective interest hence coordination and consolidation among stakeholders is less. 
In fact, the flood risk reduction for SMEs has not been optimal. The issues relate to flood risk reduction are very complex, including: weak governance [10] (Anton et al., 2015), and high vulnerability (Margono et al., 2014) [5]. Based on the background, this study aimed at analyzing the vulnerability of the area, identifying stakeholders involved in existing institutions, analyzing the significance and influence of stakeholders in flood risk reduction, and analyzing the relationships among stakeholders in flood risk reduction.

\section{Research and Methodology}

This research used mixed method approach, which is a combination of quantitative and qualitative approaches. The population of this study was the actors in SMEs in Klaten regency who had suffered from flooding. The respondents were selected through snowball sampling method by considering its suitability for identifying respondents who directly related to the study site and the efforts of flood risk reduction. Based on the method, 80 respondents were obtained for indexing the regional vulnerability and 13 respondents were selected as key informants of flood risk reduction.

In-depth interviews were carried out to obtain specific information to answer research problems and research objectives by listing questions as a guide for interviewing respondents and key informants. Interviews were conducted on selected key informants who deliberately selected based on their involvement and comprehension in issues related to the flood risk reduction.

In this research uses stakeholder analysis. Stakeholder analysis was employed to analyze the involved stakeholders in the effort of flood risk reduction. Hermans and Thissen [11] suggested stakeholder analysis as a study undertaken to identify and map stakeholders based on their role and impact in flood risk reduction. The ultimate goal was to identify complex multi-stakeholder and to determine the most significant stakeholders in association with flood risk reduction.

MICMAC is an analytical tool used to analyze power drivers and dependence power of various objectives of stakeholders. The results of the analysis show the various objectives of stakeholders as the main objectives in reducing flood risk [12]. The results of MIC-MAC analysis on the stakeholders' objectives in flood risk reduction were classified into 4 (four) quadrants. Quadrant 1 is an autonomous factor (weak influence driver weak dependent). This quadrant includes objectives that have a weak influence and dependence. The objective is less related to flood risk reduction and may have few relationships that will be eliminated from the objectives of stakeholders in flood risk 
reduction. Quadrant 2 is dependent factors (weak influence - strongly dependent). It includes objectives that have weak influence and strong dependence. The objectives in this quadrant are non-independent ones. Quadrant 3 is a linkage factor (strong influence - strongly dependent). It includes objectives that have a strong influence and strong dependence. They should be determined meticulously since the relationship between goals is unstable. Quadrant 4 is an independent factor (strong influence - weak dependent). This quadrant includes objective that have strong strength and weak dependence. The objectives are the key factor in flood risk reduction.

MACTOR (Matrix of Alliance and Conflict: Tactics, Objectives, and Recommendations) is an analytical tool used to analyze influences and interests (objectives) of stakeholders. This method is very broad because it can be used for up to 20 related purposes and yet simple and accessible. To obtain accurate results of analysis, an in-depth interview by using questionnaires is required to obtain more comprehensive answer from stakeholders [13-14]. MACTOR includes several stages of matrix preparation, namely: (1) determination of key variables and relevant actors; (2) preparation of table of actors; (3) preparation of strategic issues and objectives; (4) determination of actors and strategic objectives in the matrix; (5) calculation of convergence and divergence matrices as performed in three stages; (6) calculation of the direct and indirect relationship of power matrix; (7) calculation of the position matrix value; (8) analysis of strategic recommendations of each actor [13].

\section{Results and Discussion}

\subsection{Flood of area vulnerability}

Klaten is one of the regencies in Central Java Province. It borders on Boyolali regency in the north, Gunung Kidul regency of Yogyakarta Special Region in the south, Sukoharjo regency in the east and Sleman regency of Yogyakarta Special Region to the west. Administratively, Klaten regency is divided into 26 sub-districts. Based on the Spatial Plan of Klaten regency in 2011-2031, as many as 11 sub-districts are prone-to-flood, namely Bayat, Cawas, Ceper, Gantiwarno, Juwiring, Karangdowo, Pedan, Prambanan, Trucuk, Wedi, and Wonosari Sub-Districts.

The analysis of the flood vulnerability of Klaten Regency showed the area can be as 'moderate'. Sensitivity became the highest variable followed by adaptive capacity and exposure. Sensitivity is an aspect of vulnerability that explains the level of individual 
conditions within a society, and the environment condition when there is a flood [1516]. The income and frequency of treatment were in high vulnerability categories, while access to clean water and migration were classified in moderate vulnerability. It means that the victims were generally low-income people and yet they suffered severe impacts thus they had to conduct several treatment visits.

Adaptive capacity is an aspect of vulnerability that explains the ability of a system, region and community in the efforts of flood risk reduction (Klien, 2006) [17]. Evacuation route was classified into high vulnerability. Rivers, embankments, floodgates, floodprone maps, educational level, and distance to health services, number of NGOs, number of camp, insurance, and number of early warnings were categorized into moderate vulnerability. Evacuation sites for victims, access to flood information, emergency services, socialization and training were in low vulnerability category. Based on the categorization, several aspects should be highlighted for the optimization of flood risk reduction, including the provision of evacuation routes; the condition of river, embankment, floodgates; the existence of flood-prone map, the education level, the distance of houses to health services, the number of NGOs, the number of flood camps, and the early warning system.

Exposure is an aspect of vulnerability that explains the extent to which people are affected by floods related to vulnerable communities, location of settlement, and flood conditions [18]. Flood duration, height of inundation and distance of settlement to flood source (river) were in high vulnerability category. Meanwhile, the flood frequency and the number of elderly and toddler population were in low vulnerability category.

\subsection{Stakeholders objectives of flood risk reduction}

Regarding with the activities of flood risk reduction, stakeholders have various objectives (interests). The data of these objectives were obtained through in-depth interviews and the results were compiled into a list of stakeholders' objectives. The list of stakeholders' objectives was further processed based on structural analysis with MIC-MAC as the analytical tool. This analysis was used to describe the relationship among the objectives of each stakeholder in conducting the activities.

Figure 1 shows the objectives of stakeholders are situated in the upper left quadrant, implying they have high influence and low dependence of other variables in flood risk reduction. These objectives have major influence in reducing flood risk. These objectives are the key objectives that are critical in the success of flood risk reduction efforts. They are restoration and humanity. Restoration enables stakeholders to undertake the 


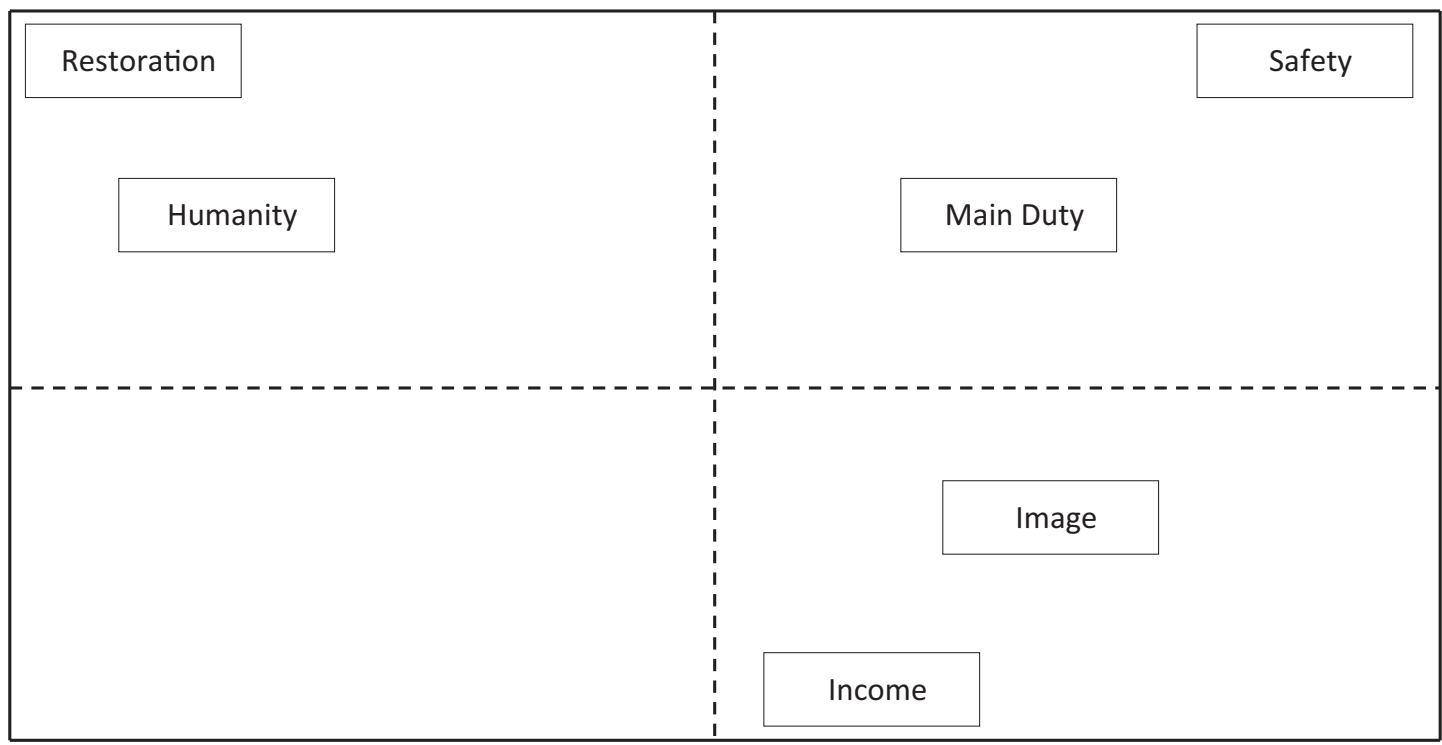

Figure 1: Stakeholders Objectives of Flood Risk Reduction Source: Stakeholder Analysis based on MICMAC (2018).

development, maintenance and improvement of natural resources and/or infrastructures, such as rivers, embankments and floodgates, which have been proven to lower the risk of flooding. Meanwhile, humanity raises awareness and empathy to others. These two objectives have an impact on reducing flood risk.

The second most important quadrant is the right-top quadrant. The stakeholder's objectives in supporting the sustainability of flood risk reduction activities. There are two objectives included in this quadrant, namely main duty (tupoksi) and safety (selamat). The objective of carrying out main duty important for government agencies because it is their main activities and also a major indicator of the performance of their agencies. The objective of promoting people's safety is also an important goal for individual or group/organization in reducing flood risk.

The right-bottom quadrant is dependent factors (weak driver - strongly dependent variables). The quadrant includes objectives that have a weak driving force and strong dependence. The element in this awareness is a non-independent element. Image, and income, are classified in this quadrant. They are the objectives of several stakeholders in conducting flood risk reduction activities.

\subsection{Model of flood risk reduction}

Optimizing the reduction of regional vulnerability level whose aspects are mentioned above should be supported by well-managed institutions. Stakeholders must synergize and continuously undertake assorted activities to eliminate the largest multiplier effects 
for flood risk reduction. The results showed there were 13 key actors (stakeholders) who have the most significant role in flood risk reduction in Klaten Regency. The stakeholders were: (1) Regional Planning, Research and Development Agency (Bappeda), (2) Regional Disaster Management Agency (BPBD), (3) Health office, (4) Department of Public Work, (5) NGOs, (6) University, (7) Head of Sub-district, (8) Village Head, (9) SMEs, (10) Volunteers, (11) Indonesian Red Cross (PMI), (12) SAR Team, and (13) TNI-POLRI.

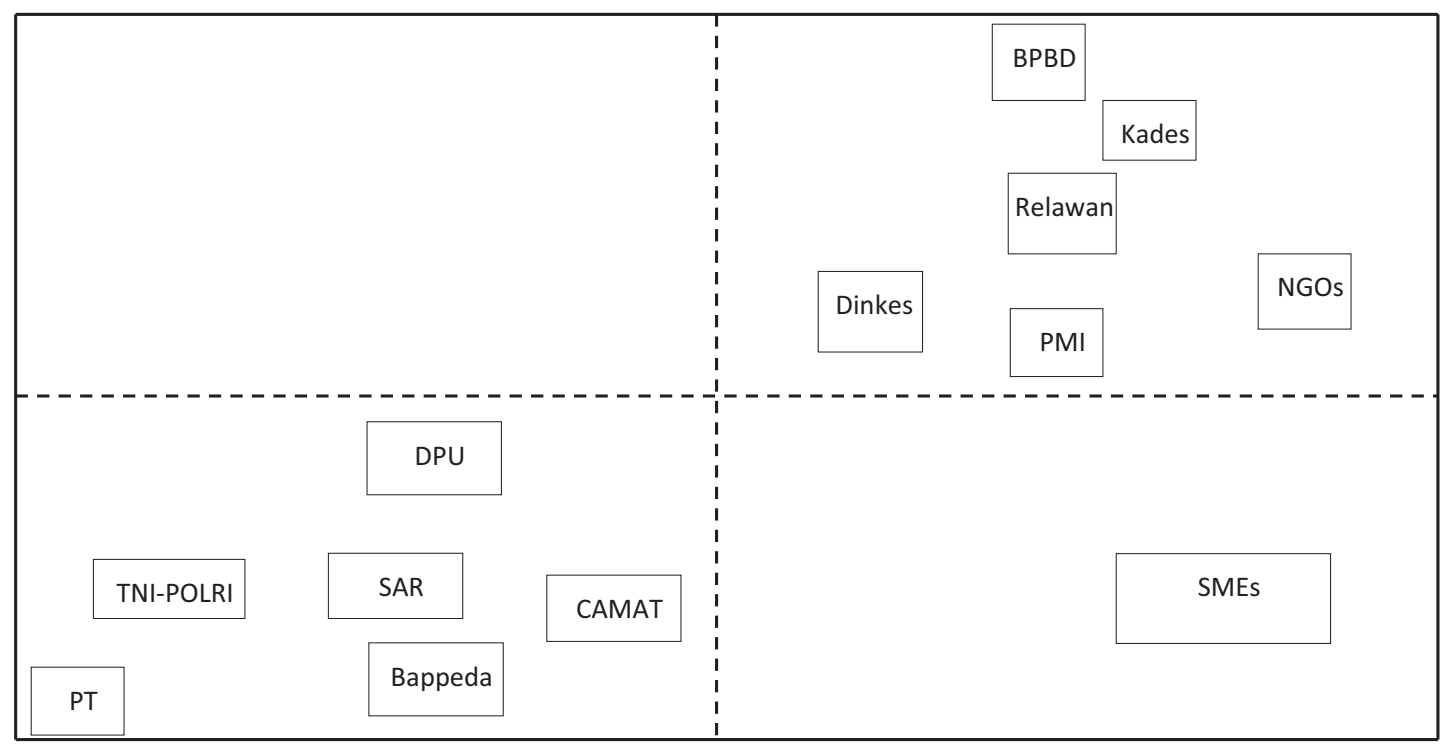

Figure 2: Map of Stakeholders' Influence and Relationship in Flood Risk Reduction Source: Stakeholder Analysis based on MACTOR (2018).

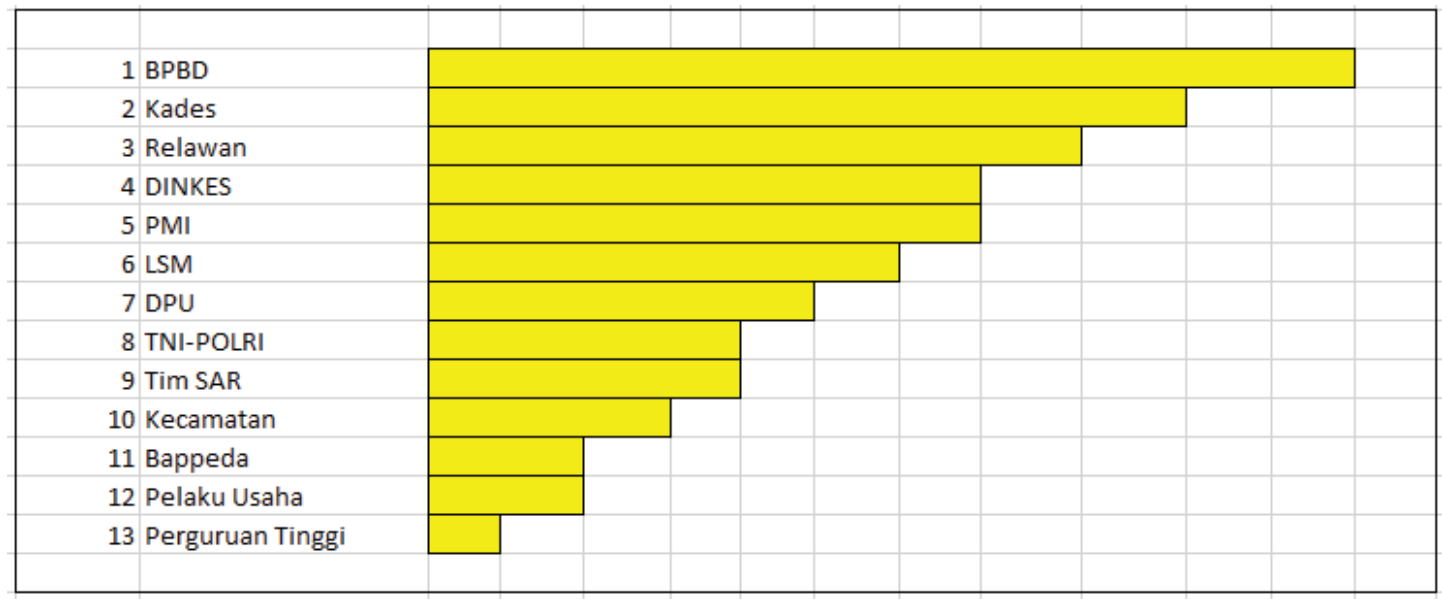

Figure 3: Actors' Competitiveness in Flood Risk Reduction Source: Stakeholder Analysis based on MACTOR (2018).

Fig. 2 and Fig. 3 demonstrate that BPBD is stakeholder that has the highest impact in reducing flood risk in Klaten Regency. As a result, it has high competitiveness and also central role in the effort to reduce flood risk. In addition to BPBD, there are two stakeholders with high influence in flood risk reduction, namely the local village head 
and volunteers. On the contrary, university is the actor with the lowest influence. It is accompanied by the head of sub-district, TNI-POLRI, DPU, Bappeda and SAR Team, which are in one quadrant with both low influence and low dependence.

Furthermore, actors with low influence and high dependence level are SMEs as the business actors, in which they are very dependent on others. It is opposed to other actors who have a higher competitiveness and a lower potential risk. It is different from SMEs are the victims of the flood disaster while other actors are those who give the effort to reduce flood risk.

The competitiveness scale with objectives as shown in Fig. 3 illustrates the income, safety, image, main duty, restoration, and humanity obtained positive response from all actors in which all actors approved this objective. In general, the actors involved in flood risk reduction activities were more concerned about personal income or profit. Nevertheless, several actors had no relation with the income aspect, i.e., TNI-POLRI, PMII and SAR. Based on the existing objectives, there were three objectives that have strong relationships, namely public safety, humanity, and main duty. Income is insignificant for stakeholders in reducing the flood risk.

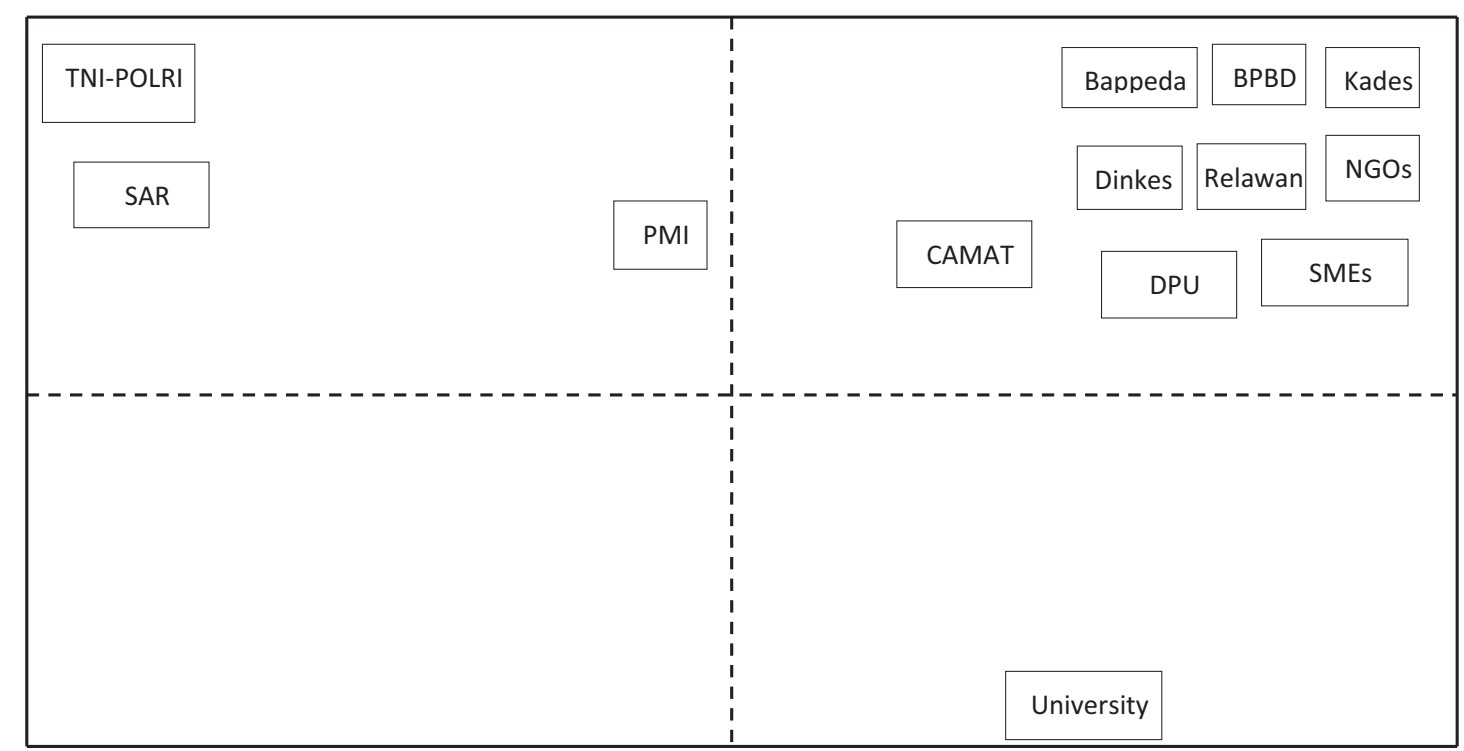

Figure 4: Map of Inter-Stakeholder Relationship in Flood Risk Reduction Source: Stakeholder Analysis based on MACTOR (2018).

Fig. 4 shows the categorization of stakeholders in flood risk reduction based on the proximity of relationships among stakeholders and their objectives. Convergence among actors in flood risk reduction indicated the strong values. The largest and most powerful stakeholder group consisted of Bappeda, BPBD, Health Office, DPU, head of sub-district, village head, NGOs, volunteers, and business actors. This group is a central 
one due to the members' high common interest level. Stakeholders with the lowest convergence level were TNI-POLRI, PMI, SAR and university. The low convergence level is because the actor has a relationship with one of the objectives or interests that are different from the others.

Convergence of stakeholders was grouped into three major groups. The first group consisted of Bappeda, BPBD, Health Office, DPU, head of sub-district, village head, NGOs, volunteer, and business actors. The second group consisted of TNI-POLRI, PMI and SAR. The third group is university. The last group is a peculiar phenomenon due to its absence of contribution in flood mitigation. It can be seen that the main actors in flood risk reduction in Klaten regency are BPBD, village officers, volunteers, and community leaders, NGOs, Health Office and DPU. These stakeholders serve as the key elements in flood risk reduction. In the arrangement of flood risk reduction institutionalization, these 7 stakeholders should be positioned as the main actors due to their significant roles.

\section{Conclusion}

Klaten regency can be classified in moderate flood vulnerability. Sensitivity is a key aspect that determines the region vulnerability, followed by adaptive capacity and exposure. In general, there are 13 key actors in flood risk reduction. They have six main goals in the flood risk reduction agenda, i.e. restoration, humanity, main duty and safety, image, and income. BPBD has a central role together with village head and volunteers in the effort of flood risk reduction. Meanwhile, university has the lowest contribution.

\section{References}

[1] Setyawan, A.A., Isa, M. \& Wajdi, F. (2012). Model pengembangan manajemen resiko bencana dan potensi pembiayaan mikro pasca bencana bagi UMKM di Kota Surakarta. Report of PPMB FE UMS - AIFDR AUSAID.

[2] Setyawan, A.A., Isa, M., Wajdi M. F., Syamsudin. (2018). Disaster as business Risk in SME: An exploratory study. International Journal of Research in Business and Social Science, 6(6), 52-63.

[3] Isa, M., Sugiyanto, FX, Susilowati, I, (2018) Community resilience to floods in the coastal zone for disaster risk reduction, Jàmbá: Journal of Disaster Risk Studies 10 (1), 7

[4] Badan Nasional Penanggulangan Bencana. (2016). Data Informasi Bencana Indonesia. Jakarta: BNPB. 
[5] Isa, M. (2016). Bencana alam: berdampak positif atau negatif terhadap pertumbuhan ekonomi?. The 3rd University Research Colloquium, Kudus.

[6] Isa, M. (2012). Manajemen resiko bisnis UMKM Kota Surakarta. BENEFIT Jurnal Manajemen dan Bisnis, 16(2).

[7] Isa, M., Sugiyanto, FX, Susilowati, I, (2015). Adaptation and mitigation model for people to restore their ecosystem from flood in Semarang, Indonesia. Jurnal Ekonomi Pembangunan, 16(2).

[8] Swart R. dan Frank R. (2007). Making Integration of Adaptation and Mitigation Work: Mainstreaming Into Sustainable Development Policies? CLIMATE POLICY 7 (2007) 288-303.

[9] McEntire, D. (2012). Understanding and Reducing Vulnerability: From The Approach of Liabilities and Capabilities, Disaster Prevention and Management, 21, 2,: 206-225.

[10] Subarudi. (2008). Tata Kelola Kehutanan yang Baik: Sebuah Pembelajaran dari Sragen. Jurnal Kebijakan Kehutanan Vol. 05:03.

[11] Hermans, L.M., \& Thissen, W.A.H. (2009). Actor analysis methods and their use for public policy analysts. European Journal of Operational Research, 196, 808-818.

[12] Mandal, Anukul dan Deshmukh, S.G. (1994). Vendor Selection Using Interpretive Structural Modelling (ISM). International Journal of Operations and Production Management. Vol 14(6). pp 52-59.

[13] Godet, M. (1991). Actors' move and strategis: The MACTOR method an air transport. Futures Journal, 605-622.

[14] Rees, G.H. et al. (2017). Data gathering for actor analyses: A research note on the collection and aggregation of individual respondent data for MACTOR. Future Journal, 9(1), 115-137.

[15] Adger, W. N. (2006). Vulnerability: Global Environmental change, 16: 268-281.

[16] Luers, A.L. (2005). "The Surface of Vulnerability: An Analytic Framework for Examining Environmental Change",Global Environmental Change 15: 214-223.

[17] Allen. (2005). Climate Change Risk and Vulnerability. Australian Greenhouse Office, Department of the Environment and Heritage, Canberra, Australia: 159

[18] Weis, S.W., Agostini, V.N., Roth, L.M., Gilmer, B., Schill, S.R., Knowles, J.E., Blyther, R. (2016). Assessing Vulnerability: An Integrated Approach For Mapping Adaptive, Sensitivity, And Exposure. Climate Change (2016) 136:615-629. 